\title{
RECURSOS DE REPRESENTACIÓN: \\ JOE SACCO Y SUS OPCIONES EN PALESTINA. EN LA \\ FRANJA DE GAZA
}

\author{
REPRESENTATIVE RESOURCE: \\ JOE SACCO AND HIS OPTIONS IN PALESTINE. IN THE GAZA STRIP
}

\author{
Mary MAC-MILLAN \\ Universidad Adolfo lbáñez de Chile \\ mary.macmillan@uai.cl
}

Resumen: Palestina es una novela gráfica del periodista Joe Sacco basada en el conflicto palestino-israelí en la Franja de Gaza. Entendemos este conflicto bélico -los abusos, las violaciones a los derechos humanos, etc.-, como un acontecimiento modernista (Hayden White) muy complejo de representar en una narración coherente y seguible. Nos interesa identificar y reflexionar sobre las opciones propias del género del cómic que Sacco utiliza para enfrentar las dificultades de representación. Para el análisis nos centraremos en la dificultad en encontrar un lugar desde el cuál testimoniar y la inclusión de un variado número de testimonios directos.

Palabras clave: Representación. Testimonio. Novela Gráfica. Palestina. Joe Sacco.

Abstract: Palestine is a graphic novel written by the journalist Joe Sacco based in the Israeli- Palestinian conflict in the Gaza Strip. We understand this belic conflict -the abuses, violations of human rights, etc.- like a modern event (Hayden White) very complex to represent in a consistent and traceable narrative. We are interested in identifying and reflecting on the own comic book genre options that Sacco uses to face the difficulties of representation. For the analysis we will focus on the difficulty of finding a place from which witness and the inclusion of a varied number of direct testimonies.

Key Words: Testimony. Representation. Graphic Novel. Palestine. Joe Sacco. 


\section{INTRODUCCIÓN}

La lectura que realizamos de la novela gráfica Palestina. En la Franja de Gaza (2004) de Joe Sacco ${ }^{1}$ se enmarca expresamente dentro del problema de la representación del acontecimiento límite. Es necesario explicar brevemente en qué consiste esta problemática y luego justificar la inserción de la mencionada novela bajo esta perspectiva. Partimos por acotar el concepto de acontecimiento límite. Un acontecimiento límite es "aquel que supera la capacidad imaginativa de concebirlo o anticiparlo. Antes de que ocurriera no fue -acaso no puede serlo- previsto ni imaginado" (LaCapra, 2006: 181). Así, el acontecimiento límite como aquel que sobrepasa todo lo imaginable presenta un problema a la narración: "este exceso del acontecimiento o el hecho sobre la facultad imaginativa-esta mendicidad de la imaginación que ha predominado, por desconcertante que parezca [...] plantea un gran desafío a la representación o el tratamiento artístico de los temas" (LaCapra, 2006: 182). Hayden White, por su parte, en El texto histórico como artefacto literario, acuña el concepto acontecimiento modernista (2003: 222-230). Este concepto complementa el de acontecimiento límite. En el acontecimiento modernista el significado de este permanece ambiguo, sobre todo para los afectados más cercanos. Presenta una resistencia a las categorías y las convenciones heredadas para asignar significados a los acontecimientos. Algunos ejemplos dados por White son: las dos guerras mundiales, la pobreza y el hambre, la contaminación nuclear y los programas de genocidio como política programada. Dicho esto, surge la pregunta ¿por qué la representación de un acontecimiento límite se presenta en sí como un problema?

Podemos distinguir entre dos tipos de problemas: los de fondo o contenido y los de forma o modo. Con los de fondo me refiero a las discusiones estrictamente teóricas, en gran parte cargadas de un lenguaje filosófico, lideradas por pensadores como LacoueLabarthe y Lyotard surgidas en relación al Holocausto. Entre los problemas de fondo destacan tres. Primero: la disyuntiva entre hablar (relatar) o callar ${ }^{2}$. Estrechamente ligado

1 Joe Sacco es un reconocido periodista norteamericano de origen maltés (1960). Es autor de numerosas novelas gráficas entre las que se destacan: Gorazde: Zona Protegida- La Guerra en Bosnia oriental (2000), La Gran Guerra (2013) y Notas al pie de Gaza (2009). Por Palestina recibe el Premio American Book Awards. Para una mirada general a su obra recomendamos The Comic of Joe Sacco. Journalism in a visual world (2015) de Daniel Worden. Sobre su método de trabajo hay varios artículos bien descriptivos: Joe Sacco on Footnotes in Gaza (2011) de Gary Groth, Reconsidering Comics Journalism: information and Experience in Joe Sacco's Palestine (2010) de Benjamin Woo y The New Journalism revisited (2007) de Rocco Versaci.

2 A modo de ejemplo citamos el caso de Jorge Semprún, sobreviviente español del campo de concentración nazi en Buchenwald. El título que Semprún escoge para su obra testimonial central grafica la dicotomía entre hablar o callar, el texto se llama La escritura o la vida. A lo largo de esta obra constantemente se reflexiona acerca de la opción correcta: callar pero seguir viviendo o escribir pero dejar de vivir. Rachel Rosenblum, en su texto ¿Sepuede morir de decir? expone la misma paradoja que subyace al acontecimiento límite. Rosenblum centra su trabajo en las experiencias de escritura de Primo Levi y Sarah Kofman, ambos escritores terminan por suicidarse y Rosenblum establece una ligazón entre la escritura y estas muertes trágicas. 
a este binomio brota un segundo problema: si al acontecimiento límite le cabe el estatuto de irrepresentable o no. Y, por último, la pretensión de verdad que lo fundamenta y su riesgo al ser un testimonio ligado a la memoria y la rememoración. Los problemas de forma/modo son concretos y se dejan adscribir a una problemática más ligada a la literatura y al lenguaje. Se refieren al modo en que el escritor arma su relato: al estilo, a las opciones narrativas, de focalización, enunciado, lenguaje figurativo versus lenguaje literal, presencia o ausencia de estetización, tendencia a la ficcionalización, etc.

De lo sostenido por diversos autores, principalmente Giorgio Agamben y Primo Levi, se desprende concretamente lo que se denomina los inenarrables. Los inenarrables son los problemas básicos que enfrenta el escritor de un acontecimiento límite. En primer lugar está el problema del lenguaje, es decir, si las palabras serían suficientes para dar cuenta de una experiencia como la guerra, la tortura, etc. Así se cuestiona el estudioso Michael J. Lazarra en Prismas de la memoria: “¿Con qué palabras se puede decir la indecible? Esta pregunta clave, tantas veces formulada a través del siglo XX, es el desafío que enfrenta todo artista o testigo-sobreviviente" (2007: 30). Este punto es significativo para la novela que tratamos ya que al ser una novela gráfica, entran a funcionar nuevos recursos que van más allá de la palabra y que son propias de la imagen. El segundo inenarrable es el que dice relación con la acogida del testimonio por parte del lector. Primo Levi, sobreviviente de Auschwitz y autor de Si esto es un hombre, ilustra muy bien esta desazón de no ser escuchado o no poder llegar al otro con la narración. Levi cuenta la recurrente pesadilla:

Es curioso que esa misma idea (aunque lo contásemos, no nos creerían) aflorara, en forma de sueño nocturno, de la desesperación de los prisioneros. Casi todos liberados, de viva voz o en sus memorias escritas, recuerdan un sueño recurrente que los acosaba durante las noches de prisión y que, aunque variara en los detalles, era en esencia el mismo: haber vuelto a casa, estar contando con apasionamiento y alivio los sufrimientos pasados a una persona querida, y no ser creídos, ni siquiera escuchados (2006: 476).

En parte, el problema de ser o no ser escuchado, de llegar o no al otro con el mensaje, no es exclusivo de la disponibilidad del oyente, sino que está ligado a las opciones narrativas del que testimonia. Así lo dimensiona también Primo Levi: ¿Hemos sido capaces los supervivientes de comprender y de hacer comprender nuestra experiencia? (la cursiva es nuestra) (2006: 497). Ese hacer comprender al que se refiere Levi, es un enorme desafío ligado a las opciones representativas del emisor.

En el texto que aquí nos convoca, Palestina, centrado en el conflicto Palestino-Israelí, Sacco hace explícito este problema al referirse al hecho de que sistemáticamente los testimonios de los palestinos no han sido escuchados y, por el contrario, la voz israelí ha 
prevalecido. Pero volveremos a este punto más adelante. El tercer inenarrable es el de definir el lugar desde el cual se narran los acontecimientos: ya sea desde el lugar de la víctima o del victimario, desde qué ideologías o toma de postura, etc.

Volcándonos ahora en nuestra novela gráfica, creemos que este marco sobre la problemática de la representación de un acontecimiento límite es útil para una lectura de Palestina. Por varias razones: el texto acoge un acontecimiento bélico complejo con muchas aristas como es la ya larga y dolorosa situación del pueblo palestino en la Franja de Gaza. El conflicto se puede leer como un acontecimiento modernista en el sentido ya citado de Hayden White. Es oscuro y de compleja comprensión y está teñido por la intromisión de los medios de comunicación. En este conflicto, Joe Sacco opta por el recurso de los testimonios para transmitir el dolor, las situaciones desgarradoras, permanentes y límite de los habitantes comunes y corrientes. Hay opciones novedosas que va tomando para revertir el inenarrable de las limitaciones del lenguaje y para ser escuchado por un mayor público. En síntesis: Palestina es una novela gráfica basada en un acontecimiento bélico límite ${ }^{3}$. Entendemos este conflicto -los abusos, las violaciones a los derechos humanos, etc.- como un acontecimiento modernista muy complejo de representar y de pasar a una narración coherente y seguible ${ }^{4}$. Nos interesa distinguir cuáles son las opciones propias del género del cómic que Sacco utiliza para enfrentar las dificultades de representación. Concretamente, las opciones y complejidades que nos interesan exponer son: 1) La dificultad en encontrar un lugar desde el cual testimoniar y las diversas oscilaciones. 2) El recurso directo de los testigos y su representación. Junto con estos puntos ejes de análisis, la lectura se enfoca en el lenguaje propio del género de la novela gráfica, el que bebe directamente de los códigos del cómic ${ }^{5}$. Es así como nos centraremos en el trabajo de viñetas que específicamente realiza Joe Sacco en Palestina: tipologías, innovaciones, efectos de lectura y de qué manera las diversas posibilidades iluminan o no la representación de los hechos de violencia que son el soporte del relato.

3 En relación a novelas gráficas bélicas, el artículo Historietas de la guerra en Bosnia: testimonio y género, hace mención al trabajo de Sacco pero centrado, ya no en Palestina, si no que en Gorazde.

4 El concepto de seguible (followability) lo tomamos de Paul Ricoeur, en su Tiempo y Narración, quien sostiene que para que en una narración advenga el sentido y la comprensión, esta debe ser seguible: "[...] proseguir una historia es comprender las acciones, los pensamientos y los sentimientos sucesivos en cuanto presentan una dirección particular" (2004: 252).

5 No entraremos en una exposición del género en cuanto tal. Sin embargo, para los que no estén familiarizados recomendamos una serie de obras introductorias: La novela gráfica de Santiago García (2010), La novela gráfica. Poéticas y modelos narrativos del compilador José Manuel Trabado (2013), The Graphic Novel. An Introduction, de Baetens y Frey (2015), The aesthetics of Comics de David Carrier (2000), Comics as Culture de Thomas Inge (1990) y Alternative Comics de Charles Hatfield (2005). 


\section{EL LUGAR DE ENUNCIACIÓN}

Uno de los problemas más complejos a enfrentar cuando hablamos del género testimonial es el del ya mencionado /ugar deenunciación. En relación a este punto, Michael J. Lazzara se pregunta: “Desde qué lugar hablan [los testigos] (posición social, ideología, género, etc.)? Los actos testimoniales siempre tienen, por cierto, una motivación; nunca son inocentes. Es, por lo tanto, sumamente necesario preguntarse cómo, por qué y con qué fines recuerdan los sujetos de historia" (2007: 61). Es decir, desde dónde habla el sujeto que emite el testimonio. Dicho lugar, en el caso de Sacco, es sumamente complejo. Describiremos a continuación este lugar y sus implicaciones para el contenido mismo. En Palestina nos hallamos frente a una triple presencia de Joe Sacco. Primero, es el autor de la novela gráfica y como tal está fuera del texto. Segundo, es un personaje más dentro de los hechos narrados $y$, tercero, es un testigo de diversos hechos complejos. Podríamos decir, ya con esta mera mención, que el lugar desde el cuál Sacco habla es ambiguo y se desplaza constantemente, haciendo difícil la fijación de un registro.

Joe Sacco como autor se presenta mediante información paratextual contenida en ambas solapas del libro (edición 2004, Planeta DeAgostini). Lo que se nos dice de él apunta a un sujeto profesional, serio, meticuloso en su modo de trabajar y nos introduce en el registro de verdad en cuanto a los hechos relatados: "Durante los meses invernales de 1991-92, durante la primera Intifada, viajó a Israel, donde convivió con judíos y palestinos en un intento de desentrañar el núcleo del conflicto entre unos y otros" (2004: contratapa izquierda). Además de esta información y datos curriculares, una foto en colores sepia avala la presencia del autor en lugares bélicos: vemos a Sacco con un gorro, lentes, un abrigo y bufanda y en el fondo una amenazante columna de humo. Se debe también considerar la introducción de Edward Said, prestigioso académico de estudios poscoloniales, quién afirma, refiriéndose a la vida en la franja de Gaza: "Con la excepción de un par de novelistas y poetas, nadie ha descrito jamás este terrible estado de cosas mejor que Joe Sacco" (2004: sin número). Es decir, Said aparece como aval de la calidad de escritor de Joe Sacco.

Ahora bien, como personaje, Sacco se presenta con dos rasgos dominantes. En cuanto a la modalidad de representación icónica opta por una auto-representación hiper caricaturizada. En cuanto a los rasgos de carácter o de comportamiento, su opción es la de la figura del anti-héroe. La caricatura busca una identificación rápida y fuerte con el personaje. Tal es la función que Scott McCloud postula en su ya clásico Understanding Comics. The invisible art. McCloud considera una paleta de opciones icónicas que van desde un punto extremo de realismo, en el cual encontramos la fotografía; hasta el otro extremo de representación simbólica, ocupada por la caricatura (o la carita de smile):"By stripping down an image to its essential meaning, an artist can amplify that meaning in 
a way that realistic art can't" (1994: 30). Según McCloud, la ausencia o disminución de elementos ligados a la estética realista contribuye a una mayor identificación del lector con el personaje: "When you look at a photo or realistic drawing of a face you see it as the face of another. But when you enter the world of the Cartoon you see yourself" (1994: 36).

Es el caso de Joe Sacco, quien se representa en Palestina mediante un ícono caricaturesco y con elementos de muy rápida identificación: como son los lentes redondos, su gran nariz y boca de labios en extremo anchos. La función de esta caricatura de sí mismo, además de la identificación, según Melero, sería la de graficar la distancia con los palestinos: "Para su proyección gráfica, el autor recurre a un dibujo ligeramente feísta y caricaturesco, en contraste con la representación figurativa del resto de personajes. Quizá, porque esta banalización de sí mismo enfatiza la épica y el protagonismo de los demás" (2012: 552). Es así como ya desde esta opción icónica Sacco muestra su complejo lugar de enunciación: es y no es parte de los acontecimientos narrados, pertenece y no pertenece a las historias testimoniadas. A este recurso gráfico propio del cómic se añade la presentación como anti-héroe. Sobre la figura del antihéroe, Javier Melero afirma: “La imagen de Sacco, su aparente neutralidad ideológica, su comportamiento anti-heroico, evoca los rasgos de un ser humano corriente. Esta representación facilita la identificación del lector y la proximidad de Sacco a los protagonistas, aligera el peso histórico del relato hasta situarlo en un nivel de interpretación más humano de los acontecimientos" (2012: $552)^{6}$. El antihéroe es una figura que pone en evidencia los complejos límites entre los buenos y los malos, entre el blanco y el negro. En relación a este punto creemos que el antihéroe se puede entender también a la luz del concepto de zona gris de Primo Levi. Primo Levi acuña su zona gris para referirse a situaciones límites en las que la nomenclatura de víctima/victimario, culpable/inocente, etc., se ve desbordada para dar cuenta de la realidad. Levi critica la costumbre cómoda y reduccionista de ver la historia siempre en dos bandos:

La historia popular, y también la historia tal como se enseña tradicionalmente en las escuelas, se ve afectada por esta tendencia maniquea que huye de las medias tintas y la complejidad: se inclina a reducir el caudal de los sucesos humanos a los conflictos, y el de los conflictos a los combates; nosotros y ellos, atenienses y espartanos, romanos y cartagineses (2006: 497).

Frente a esta simplificación Levi postula una zona compleja e intermedia. En relación a la situación concentracionaria en los Lager nazis, afirma: "el enemigo estaba alrededor, pero dentro también, el nosotros perdía sus límites, los contendientes no eran dos, no se

6 La frase se refiere a Notas a Pie de Gaza, otra obra de Joe Sacco, pero se deja perfectamente aplicar a Palestina ya que es el mismo recurso. 
distinguía una frontera sino muchas y confusas" (2006: 498). En este sentido, Joe Sacco representado como un antihéroe se mueve precisamente en una zona gris, no termina del todo por fijar su posición. Por momentos es cercano a la causa palestina, otras veces la critica expresamente. No se halla en Palestina la clara estructura de víctima/victimario en relación a la dupla Palestina/ Israel. Para dar un solo ejemplo: Sacco visita un hospital lleno de heridos palestinos, una niña de colegio cautiva su atención, ha sido herida de bala en su colegio. Sacco matiza su condición de víctima: "la niña es un encanto...Se me cae la baba...Pero pongamos su encanto de lado [...]... No es que no fuera culpable... Durante la segunda visita canta de plano... Intenté tirar una piedra, pero los soldados fueron más rápidos" (2004: 34). Sacco nos introduce en la Zona Gris del conflicto. Su figura de anti-héroe, se muestra, además, en variados momentos en que precisamente su estatura moral o dignidad como sujeto tambalea. ¿Qué implicancias tiene esto para el testimonio mismo? Jaume Peris, en su estudio La imposible voz, en una especie de crítica a los planteamientos tradicionales sobre el testimonio, plantea un vuelco en el enfoque y hace hincapié en lo que denomina ética de la representación por sobre las modalidades de representación: "la noción de responsabilidad debe planear sobre los modos en que esa violencia puede ser dicha. Toda una ética de la representación se juega en ello" (2005: 20). Este énfasis en la asunción de una responsabilidad que le cabría al testigo se ve problemática en el caso de Sacco y su opción por la representación de su propio "personaje-Sacco" como antihéroe. Por momentos pareciera que sus opciones pondrían en evidencia una falta de compromiso, una ausencia de lugar entendido como una ideología o toma de postura. Pero el asunto es más complejo que esto. Siguiendo a Peris, este afina su noción de responsabilidad del siguiente modo: “Una responsabilidad que en términos generales podemos pensar como el reconocimiento de hallarse en un lugar marcado por una doble imposibilidad: por la imposibilidad de saber y por la imposibilidad de decir" (2005: 21). Lo que proponemos es juzgar entonces la opción del antihéroe a la luz de estas dos imposibilidades: la del saber y la del decir. Constatamos un Joe Sacco más prudente u oscilatorio en relación a la verdad de los acontecimientos entre palestinos e israelitas (saber). A su vez, un Sacco irreverente por momentos en su lenguaje (decir), dado el estatuto complejo de los hechos bélicos, siempre plausible de ser leído bajo una versión contraria; nos parece, más que una negación a asumir una postura, un gesto de responsabilidad y de prudencia. Veamos algunos ejemplos de este Joe Sacco antihéroe.

Desde las primeras páginas se muestra como un infiltrado, ejerciendo un claro juego con el lugareño. Es un seductor y huésped perfecto que hace lo necesario para conquistar al entrevistado, pero que, sin embargo, no pertenece a ese mundo. Sacco se maneja con un doble código con los lugareños. Por un lado está lo que piensa de ellos, y, por otro, lo que deja ver o su actuar. A esta doble perspectiva o cinismo accedemos como lectores 
mediante el uso de cartuchos que están dirigidos a nosotros y que dan cuenta de su pensamiento, el que choca o genera roce con los diálogos que se representan mediante los globos.

Un solo ejemplo de este cinismo que se mantendrá a lo largo de Palestina lo hallamos en las páginas 4 y 5 . Sacco se encuentra caminando por las calles de Nablús y está presto a entablar contacto con un lugareño, nos advierte a los lectores: "Tres semanas después ya soy bueno en esto, observa su reacción, porque ahora estoy en la Ciudad Antigua de Nablús y ambos sabemos que no soy de aquí, y ahora observa..." (2004: 4). Lo que viene es un diálogo con un lugareño en el que Sacco se muestra como hábil conocedor de los saludos y de los estrictos códigos sociales pautados. Es invitado a tomar té y no lo desea pero acepta igual. A los lectores nos dice: "Lo ves, me solicita, quiere practicar su inglés, quiere saber qué hago aquí, qué pienso de su país" (2004: 4) y continúa describiendo la ceremonia del té: “¡Té! ¡Muy azucarado! ¡La hospitalidad se mide en terrones! Pero soy cortés [a nosotros]. Me encanta el té [al lugareño]. Un huésped perfecto en Palestina" (2004: 4). Luego describe el diálogo con el lugareño, en el que se muestra evasivo frente a la pregunta sobre qué piensa él del país. Lo que me interesa aquí, más que ahondar en el ejemplo, es dar cuenta de esta doble estructura en la que se nos revela a los lectores la no concordancia entre un cierto actuar y un pensar, lo que tiene como efecto el cinismo.

Otro ejemplo de este cinismo lo vemos en un encuentro casual en un taxi. Un angustiado joven le solicita que le consiga información sobre becas para ir a Estados Unidos. Sacco se muestra atento y acepta sus datos, y a continuación nos dice en un cartucho: "Me garabateó su dirección, yo me la metí en el bolsillo y lo olvidé para siempre" (2004: 28). Además de este cinismo son numerosos los rasgos anti-heroicos que se despliegan a lo largo de su estadía en Palestina: vemos un Joe Sacco erotizado y vulgar, cobarde, abusador, glotón, miedoso, morboso y ególatra. Al ver a las jóvenes soldados israelíes confiesa: “De tanto en tanto, qué le voy a hacer, me deslizo a la carretera de Jaffa para echarles una ojeada a las nenas adolescentes de permiso...Solo para recordarme a mí mismo que me estoy volviendo un viejo rijoso..." (2004: 16). Y, a continuación, refiriéndose al desplante y fuerza física de los soldados: “ ${ }$ Hasta yo me esfuerzo por no abrirme de patas! (2004: 16). Cuando se encuentra sobrepasado por los asedios de los vendedores en el comercio callejero, dice: "Me gustaría darles de patadas" (2004: 24). Otras veces deja correr su glotonería al ser invitado a la mesa por anfitriones que no son precisamente ricos $(75,174)$ o sale corriendo de algún punto de conflicto callejero, asustado por las manifestaciones: "soy un cagueta de primera" (2004: 122).

En fin, el resultado de la caricaturización más la suma de la representación antiheroica es un personaje que no basa la autenticidad de su testimonio en argumentos adhominem. No es en su estatura moral en la que habremos de encontrar asidero para creer o no creer en una verdad. Las opciones hasta aquí mostradas nos internan en un elemento 
que es propio del género que estamos tratando. Un narrador en primera persona, autobiográfico y de testigo-implicado es común en la novela gráfica. Para leer a Sacco es necesario insertarlo dentro de un determinado movimiento dado por la novela gráfica en los años setenta. Según Susana Arroyo, en su artículo "Formas híbridas de narrativa: reflexiones sobre el cómic autobiográfico": "la incursión del cómic en temas no ficticios a partir de los setenta ha resultado fundamental para restaurar poco a poco su imagen ante los ojos del público y de la crítica. De ser una forma menor de entretenimiento, el comic ha pasado a ser considerado un medio con capacidad expresiva suficiente como para abordar directamente la realidad" (2012: 105). El surgimiento de voces más íntimas y autobiográficas obedecería a un movimiento generalizado que habla de un cambio de paradigma y que se ubica como un fenómeno propio de la posmodernidad7. La creciente opción por lo autobiográfico tiene sus raíces en un profundo cambio referido a la pérdida de confianza en narrativas más tradicionales, como señala Arroyo: "el desarrollo del cómic autobiográfico y su progresiva instalación en el canon artístico desde principios de los setenta coincide cronológicamente con la tendencia generalizada en otros medios artísticos a rechazar los tradicionales metarrelatos ideológicos y tomar los discursos privados como cauce privilegiado de expresión" (2012: 121). Es dentro de este contexto que leemos las opciones ya descritas de Joe Sacco.

Retomemos el punto del lugar desde el cual habla Sacco. Habíamos dicho que era triple: como autor, como personaje y como testigo. Hay un cierto desajuste entre el lugar del autor y el del personaje, ya que el personaje se muestra muy cargado hacia esta mostración de la humanidad más baja del sujeto. Esto se contradice con la información más sobria y curricular de los paratextos. Un segundo desajuste se haya al evaluar el lugar de testigo ocupado por Sacco. Como testigo Sacco opta, casi en su totalidad, salvo algunos breves quiebres, por dar su voz a los entrevistados. Esto está obviamente ligado a su estatuto de periodista, en el que cede casi íntegramente su voz a las voces de los testimonios de los palestinos. Esta suerte de negación de su propia voz tiene matices que se dan gracias a las técnicas propias del género de la novela gráfica. Se trata de una presencia que se haya, ya no a nivel de contenido, sino a nivel de forma. Para explicar este punto habremos de entrar de lleno a describir la representación de los testimonios.

7 Tal como explica Susana Arroyo en el mismo artículo citado: “Desde los setenta, las esferas sociales y artísticas han vivido un proceso democratizador gracias al cual todo ciudadano se convierte en un ser importante y, por ende, con derecho a contar su historia privada (a tener sus quince minutos de fama). Esta creciente importancia del individuo y de las pequeñas historias personales se refleja bien en fenómenos sociales contemporáneos como el auge de los blogs, los reality shows, los talk shows, el periodismo ciudadano, el amateurismo artístico, etc., pero también en el fuerte desarrollo de los géneros literarios autobiográficos" (2012: 110). 
Pero en relación al lugar desde el cuál narra Sacco, podemos resumir diciendo que es casi una negación a asumir un determinado punto de vista, hay casi una búsqueda de anulación. Anulación que como ya proponíamos arriba al hablar del anti-héroe, no implica una ausencia de responsabilidad. Leemos en este gesto u opción una ética de la representación. Esta opción se entiende o se justifica a la luz de la presencia enorme que toman los testimonios. Y sobre todo a partir de la particular teoría que el mismo Sacco expone al comienzo sobre la importancia de llegar al lector desde una cierta afectividad. Recordemos el segundo inenarrable mencionado en la introducción: la dificultad en encontrar un eco en el lector y el riesgo de que éste simplemente pase por alto la radicalidad de los hechos. La teoría de Sacco es que la postura de los israelíes ha tenido una clara acogida en el mundo occidental por sobre la de los palestinos. Esto se debería a que la prensa y los diversos medios de comunicación han sabido presentarnos a los israelíes como sujetos cercanos: con rostro e historia cotidiana, permitiendo así una clara identificación. Sacco da como ejemplo el impactante caso de Klinghoffer, un adinerado judío americano que fue víctima del terrorismo palestino y fue arrojado al mar en su silla de ruedas desde su barco en un crucero de placer. En diálogo con una amiga sostiene: "Has de entender los medios de comunicación estadounidenses. Quieren interés humano. Asesinan a Klinghoffer y nos hacen el retrato completo, la viuda inconsolable, dónde vivía y qué cereales se tomaba... así hasta que lo ves como el tío de la puerta de al lado que te pide una escalera de mano. ¿Sabes qué poder tiene eso?" (2004: 6). El poder de este interés humano, de acercar a la víctima a al lector es enorme, tanto así que Joe Sacco declara: "qué eran los problemas de los palestinos frente a Klinghoffer, que comía cereales de tal o cual marca y probablemente me habría pedido la escalera de mano...?" (2004: 8). Y sentencia: "cayó por la borda del Achille Lauro y lo hizo en mi conciencia" (2004: 8). Este lo hizo en mi conciencia es lo que precisamente, a los ojos de Sacco, falta en los relatos de las víctimas palestinas: "Y si los palestinos llevan décadas hundiéndose, expulsados, bombardeados, molidos a palos, aunque salgan por la noche en las noticias nunca puedo retener un nombre o una cara, por no hablar de sus cereales" (2004: 8). A la luz de la teoría del acercamiento humano -la que Sacco centra humorísticamente en los cereales- leemos su opción por desaparecer bajo la serie de testimonios recogidos en su Palestina.

Así, ese aparente nolugar, esa disminución de su propioyo a favor de los otros, obedece a una ética de representación. Recojamos la pregunta de Lazzara citada al comienzo: ¿desde qué lugar habla Joe Sacco? ¿Cuál es su motivación? Sacco habla claramente desde un lugar ético. Su motivación es que veamos a los palestinos como a ese vecino que nos pide la escalera de mano. Y luego, en un segundo momento, su motivación es incidir claramente en la transformación de la realidad. Si ese otro palestino es mi vecino, entonces asumiré su dolor y desdicha como algo mío. Su objetivo final es político, en el 
mejor sentido de la palabra, como se lee en su brevísimo prólogo: "Los pueblos palestino e israelí continuarán matándose entre sí en un conflicto de baja intensidad o con una violencia desgarradora [...] hasta que este hecho central (la ocupación israelí) se trate como un tema de ley internacional y de derechos humanos básicos" (2004: Prólogo del autor, sin número). Dicho esto, es necesario ahora entrar de lleno en la descripción de los testimonios: ¿cómo los trabaja? ¿Cómo construye este complejo espacio de una voz ajena?

\section{LA REPRESENTACIÓN DE LOS TESTIMONIOS}

Damos primeramente algunos datos concretos acerca de los testimonios contenidos en Palestina. Contamos un número de 28 testimonios, que poseen, por lo general, una extensión breve de no más de 3 páginas. Muchos solo son de 1 página ó 2 . Los que sobresalen de esta norma, y que merecen análisis aparte, son tan solo tres: de 9, 11 y 12 páginas. Los temas o hechos testimoniados giran en torno a los siguientes problemas: la expropiación y destrucción de casas por parte de los israelíes, los heridos civiles en enfrentamientos callejeros y las dificultades de los hospitales, la difícil labor en los colegios, la masiva destrucción de los olivos y por lo tanto el medio de subsistencia de incontables familias palestinas, los continuos y aleatorios ataques de colones israelíes a vecinos palestinos, la dolorosa pérdida de hijos para las madres palestinas en situaciones de suma arbitrariedad, las largas e injustificadas estadías en la cárcel de Ansar, los interrogatorios y los métodos de tortura, la experiencia de los adolescentes y preadolescentes que se han unido a la resistencia, los minusválidos y heridos y su reinserción familiar y social. Se trata de un largo y agotador lamento que apunta a mostrar la realidad del palestino promedio como un estado de excepción eterno. En éste, la pobreza, el hacinamiento, la ausencia de puestos de trabajo, la falta de recursos y los abusos e injusticias constantes de los israelíes son el pan de cada día. En relación al método de trabajo de Joe Sacco, este sigue los planteamientos del periodismo de reportaje, y en esto es sumamente riguroso. Viaja al lugar mismo de los sucesos, siempre se hace acompañar por un lugareño amigo que oficia tanto de traductor como de guía social y mediador. Se entrevista con los afectados: sean hombres, mujeres, chicos, trabajadores, profesionales o no. En ese sentido, su mirada es transversal y busca el testimonio directo, sin importar ni edad ni nivel cultural del sujeto. Rechaza entrevistas que no sean de primera mano, es decir, testigos oculares de los acontecimientos. En la entrevista se vale de varios recursos, toma notas y fotos y posteriormente elabora esa información en formato de cómics.

A continuación describiremos concretamente la estructura de las entrevistas y las técnicas propias de la novela gráfica que utiliza Sacco. En un segundo momento ahondaremos en tres ejemplos de testimonios que nos parecen más logrados y que son los más extensos. Para 
finalizar evaluaremos este trabajo del testimonio dentro del marco mayor del problema de la representación de un acontecimiento límite. Puntualmente: ¿logra Sacco efectivamente comunicar la experiencia palestina y superar el inenarrable del receptor? ¿Es fiel a su propuesta inicial de mostrar a las víctimas como vecinos que comen tal o cual cereal?

\subsection{PROCEDIMIENTO GENERAL}

En las 28 entrevistas se puede distinguir un cierto patrón estructural que se mantiene por sobre las posibles variaciones. Sacco suele comenzar con una viñeta de plano general que sirve como contextualización del lugar dónde se lleva a cabo la entrevista: el living de una casa, la oficina de una doctora, etc. En esta primera viñeta no se observa un recuadro que la delimite, la escena desborda y domina la página como un telón de fondo. El relato del informante se nos da de modo directo mediante globos de diálogo. A continuación, Sacco opta por viñetas menores claramente delimitadas en las que la narración del testigo se nos ofrece a modo de voz en off contenida en un cartucho y entrecomillada. El relato del testigo es traducido a imágenes, es decir, en la viñeta se observa el relato de lo que la voz en off nos va relatando. Así, pasamos del living de la casa a la escena misma en vivo y en directo. Sacco privilegia hábilmente la visualidad del relato por sobre la mera escucha del testimonio. Luego se vuelve a una viñeta por lo general en primer plano del rostro del informante con globos de diálogo. Para finalizar con una vuelta a viñeta de plano general con la que cierra el encuentro.

Esta estructura modelo, con algunas variaciones en el largo o vueltas al rostro del informante, es extremadamente potente. Por un lado, prima la circularidad del relato, cercado por las viñetas contextualizando el espacio de la entrevista y, por otro, el recurso de la voz en off es muy efectivo para vivir más presencialmente la historia misma. A esta estructura base descrita se observa, en algunas ocasiones, el añadido de cartuchos que corresponden a informaciones adicionales que provienen de Joe Sacco. En estos cartuchos, algunos bastante extensos, Sacco le entrega al lector información dura, con cifras cuantiosas que vienen a complementar el relato del sujeto. Dicho de otra manera, Sacco no desea que perdamos de vista el contexto en el que se debe leer el testimonio. Su intervención mediante los cartuchos no obedece tan solamente a su mirada u opinión personal, sino a un periodismo de datos que iluminan la situación. Veamos algunos ejemplos. Al finalizar la entrevista con las familias a las que les habían cortado los olivos, Sacco añade el siguiente cartucho alargado: "Y lo suyo es solo una gota en el mar de lágrimas ¿Seis árboles de palestinos? ¿17? ¿70? Pse. Los israelíes arrancaron más de 120.00 durante los primeros cuatro años de la Intifada... Por "razones de seguridad", como en este caso... O para la construcción de la red de carreteras que conecta los asentamientos con Israel..." (2004: 62). Los cartuchos pueden contener su cuota de ironía 
o de comentario ácido mediante el cual se puede establecer cuál es la opinión personal de Sacco en relación a tal o cual tema. No obstante, el mayor peso de esta técnica es la del choque. En el mismo tema de los olivos, en un cartucho aparte se introduce la voz del primer ministro israelí Shamir, quién dice en un globo directo: "Es totalmente natural que establezcamos un asentamiento aquí o ampliemos otro allá. Actuamos de acuerdo con el criterio que la tierra nos pertenece" (2004: 63). El choque entre el testimonio puntual de las familias palestinas a las que se les ha privado de su fuente de producción y la cita desfachatada del primer ministro es un logro interesante de este recurso de Sacco.

Veamos otro ejemplo del uso del cartucho informativo que produce un fuerte choque irónico. Un padre de familia relata, siguiendo la misma estructura ya descrita (primero viñeta de contexto, voz en off con el relato y vuelta a rostros en primer plano) como los colonos asesinaron a tiros a su primo y a su hermano. Debido al toque de queda impuesto por los mismos israelíes, el hermano murió de un largo desangramiento. Los testigos añaden que han presentado una demanda en contra del colono que disparó. Es aquí cuando Sacco introduce un cartucho con información que nos permite leer la muerte de dos personas dentro de un marco mayor:

De diciembre de 1987 a octubre de 1991, los colonos han matado a 42 palestinos, y en ese tiempo solo han concluido tres juicios. ¿La sentencia más dura? Tres años. Por otra parte, los palestinos han matado a 17 colonos durante ese mismo período. Seis de los nueve sospechosos detenidos por estos incidentes han sido condenados a cadena perpetua; otro lo ha sido a 20 años; se han derribado seis viviendas familiares (2004: 71).

En ocasiones, estos cartuchos llegan a ser bastante extensos, produciéndose un desbalance entre el testimonio y esta información. Tal es el caso de la casi digresión acerca del Informe Landau, en el que se autoriza a la Shin Bet, organismo de investigación israelí, a usar medios de presión tanto psicológico como presión física moderada (2004: 95). El desbalance, a muestro juicio, resta fuerza al testimonio. Ya no queda claro si el cartucho es un complemento del testimonio o, por el contrario, éste complementa al cartucho.

\subsection{TESTIMONIOS EXTENSOS}

Como mencionábamos anteriormente, tan solo tres testimonios poseen una extensión mayor (de 9, 11 y 12 páginas), y más allá de la extensión, hay en ellos recursos nuevos importantes de señalar.

En el capítulo "presión moderada", segunda parte (2004: 102), Sacco recoge, a lo largo de 12 páginas, el testimonio de un padre de familia de clase media que fue detenido por 
presunta sospecha. Al comienzo todo se da como en el modelo tradicional ya expuesto: nos sitúan en el living de la familia y de un momento a otro pasamos a las viñetas con la voz en offy el relato en vivo y en directo. La diferencia con lo hasta aquí visto es la estrategia de ir aumentando el número de viñetas en cada página. Este aumento de viñetas va saturando la página y su aumento corre parejo con los acontecimientos expuestos. Nos explicamos.

En el momento de la detención del supuesto sospechoso, Ghassan, la que ocurre en la noche en su casa, Sacco utiliza 3 viñetas: una de media página superior y dos medianas para la mitad inferior de la página. De ahí pasa a 6 viñetas de igual dimensión que muestran a Ghassan esposado, vendado y llevado a un centro de detención. En la página siguiente el relato que continúa hasta el final narrado en primera persona en voz en off, se nos da en 9 viñetas. De ahí pasa a 12 viñetas por página, luego a 16 por página. Es decir, la página cada vez se llena más con las imágenes oscuras y de encierro del detenido. Lo vemos sufriendo por horas amarrado en una silla, encapuchado y adolorido. De 16 viñetas por página pasamos a 20 pequeñas viñetas, lo que se sostiene a lo largo de 4 páginas. Estas cuatro páginas coinciden con el punto álgido del relato de "presión moderada". Ghassan, producto del encierro y las posturas empieza a tener alucinaciones, su percepción se ve alterada: su hija, su padre y su hermano se le aparecen muertos y Sacco los incluye en las pequeñas viñetas. Al aumento de viñetas por página, que origina una saturación visual, se le agrega el uso de una tira (strip) negra y ancha que contribuye a la sensación funesta, de oscuridad y encierro. La última página, en la que el detenido es liberado y sale a la calle, se reduce de un golpe de 20 viñetas por página a 7, dando ópticamente una sensación de apertura y libertad. De hecho, las siete viñetas, en esta página, se distribuyen en seis viñetas medianas en la parte superior y una grande que ocupa toda la media página inferior. La última viñeta es muda y se nos ofrece en una perspectiva general la focalización del propio Ghasan que camina nuevamente libre por las calles y el gentío de la ciudad. El fondo, en contraste con la oscuridad de las viñetas pequeñas, es un cielo blanco despejado con un punto de fuga que se ubica en la lejanía.

En resumen: la técnica ocupada por Sacco, de ir aumentando el número de viñetas por página en una saturación visual progresiva a la tensión del relato y luego despejar bruscamente el campo visual en el momento de la liberación, añade una experiencia performativa a la lectura. El testimonio no solo es visualizado como en la técnica de la voz en off y el cartucho, sino que además se le suma una cierta experiencia sensorial que reproduce icónicamente la experiencia de la presión moderada. Mismo trabajo de tensión y de ritmo utiliza para el testimonio de una anciana madre que pierde dos hijos en un breve lapso de tiempo. Se trata de 9 páginas (235-243) en las que también va saturando la página con el aumento del número de viñetas, si bien no es tan marcado como en el ejemplo anterior. Por último, el tercer testimonio extenso de 11 páginas se centra en tres testimonios de detenidos en la cárcel de Ansar III y su estadía en ella (83-92). Dos nuevos 
recursos se suman a las técnicas ya descritas. El más novedoso es el añadido de una pequeña imagen tipo foto de carnet de identidad con el rostro del testigo que acompaña al cartucho con voz en off. Por un lado, los cartuchos son más extensos para contener el relato más detallado de la estadía en el centro carcelario, y la foto ayuda a seguir el relato con mayor facilidad. A esto se le suma la novedad de ir intercalando tres testimonios: Yusef, Mohammed e lyyad, todos profesionales de mediana edad. La intercalación otorga mayor credibilidad al relato ya que los testimonios se complementan y reafirman, de ahí que la mencionada foto en el margen superior ayuda a seguir correctamente la voz del narrador. En general, estos tres testimonios, tanto por su extensión como por las técnicas explicadas, pueden considerarse como los más logrados.

\section{EVALUACIÓN}

Hemos visto tanto el tema del lugar como el de las variadas técnicas utilizadas para transmitir los testimonios. Es necesario ahora retomar el problema de la representación e intentar una evaluación del trabajo de Joe Sacco en Palestina. Para ello es importante recordar la propuesta inicial que el mismo Sacco explicita al comenzar su novela gráfica (2004:6-10).Sacco sostenía la urgencia de humanizara los palestinosylograr un vivo retrato de ellos. En relación a la posible identificación entre el lector y los sujetos entrevistados en Palestina -punto clave para la ética de Sacco que para resumir hemos denominado de los cereales- creemos que este punto no se logra del todo. Varios son los elementos que se confabulan para que el logro sea tan solo parcial. Hay motivos técnicos que apuntan a las opciones representativas del mismo Sacco, y hay otros motivos externos de la propia situación límite palestina. Las opciones de Sacco que dificultan la identificación son básicamente dos: por un lado la brevedad de los testimonios, y, por otro, la opción de representación iconográfica caricaturesca. Recordemos, Sacco decía: "nunca puedo retener un nombre o una cara" (2004: 8). ¿Puede el lector de Palestina, luego de su lectura, "retener algún nombre o alguna cara"? La verdad es que es difícil. Lo dificulta la brevedad de los testimonios, los que carecen de una suficiente contextualización biográfica del sujeto. El efecto de lectura es más bien de acumulación que de interiorización. Joe Sacco no profundiza en ningún testimonio, ni siquiera en aquellos más extensos ya analizados arriba. Si el lector logra recordar, con más probabilidad el testimonio del padre de familia torturado, lo recordado es el hecho de la tortura, pero no a la persona torturada.

En relación con el atentado de Klinghoffer, Sacco, recordemos, señalaba:"cayó por la borda del Achille Lauro y lo hizo en mi conciencia"(2004: 8). La persona torturada no logra entrar en mi conciencia. No logro imaginármelo como a un vecino que me pide prestada la escalera de mano. Y la opción por la cantidad, más que la profundidad, es uno de los motivos centrales para que no ocurra el fenómeno deseado. Incluso, es el mismo Joe Sacco- personaje quién 
alude a esta imposibilidad de retener a la persona humana detrás del testimonio. Cansado de oír tantos relatos, Sacco deja aflorar su indiferencia: "una y otra vez, las mismas historias, quizá con algunas contusiones de más o de menos. ¿Y quién es esta gente? Me los han presentado, pero no recuerdo ningún nombre. ¿Y dónde estoy? Campo de Nuseirat. ¿No-seirá? ¿No-se-qué? (2004: 152). Aflora con fuerza en las líneas citadas el anti-héroe, el personaje común y corriente desbordado por la realidad. Si hay humanidad en algún personaje de Sacco, si logro imaginarme a alguien como mi vecino solicitando una escalera de mano, es, paradójicamente -más que cualquiera de sus entrevistados palestinos- él mismo.

Es a Joe Sacco a quién el lector acompaña por toda su larga y agotadora travesía por la Franja de Gaza: con él entramos a los campos hacinados, con él pasamos miedo por las escaramuzas callejeras y con él sufrimos y nos agotamos. Resulta extraño, en relación a este punto -el de la brevedad y descontextualización de sus testimonios- que Sacco sea completamente consciente de su estilo y que sin embargo persista en él. Hacia el final de su estadía nos ofrece la más breve de todas sus entrevistas: una única página con 8 viñetas que reproducen magistralmente la pauta ya explicada. Una primera viñeta de contextualización espacial de plano general en la que Sacco se saluda de la mano con el entrevistado, le sigue una viñeta de rostro en primer plano, luego cuatro viñetas con la narración gráfica de la víctima y los cartuchos con su voz en off para volver a una viñeta del rostro del testigo con su narración directa en globos. La octava y última viñeta cierra el encuentro y vemos a Sacco y a sus acompañantes en un plano general saliendo de la casa del entrevistado y subiéndose a un auto. Esta última viñeta contiene un cartucho en el que se lee: “ Eso es todo! ¡Una entrevista rápida! Toda una tragedia en menos de 20 minutos..." (204: 246). Pare él fueron 20 minutos, para los lectores 8 viñetas de tamaño mediano en una única página. "Toda una tragedia en 20 minutos", la frase revela la plena autoconciencia que Sacco posee de sus opciones representativas. Si Sacco es consciente de esta compresión de sus relatos, de estas tragedias envasadas y aprisionadas en pocas viñetas, ¿por qué propone al comienzo de su obra una estética del cereal que no llega a concretar? Hay aquí una evidente incongruencia entre la meta fijada y las opciones representativas tomadas. Me limito a constatar esta paradoja. Le compete a su propio autor, más que a un lector, el esclarecerla.

Lo único que podríamos señalar a modo de explicación es que al fin al cabo primó la fuerza de la disciplina de su autor. Joe Sacco es un periodista que bebe de las fuentes del periodismo reportaje y no es un narrador literario. Eso por un lado, y por otro, la necesidad de reunir una cantidad suficiente de testimonios que, aunque breves y que terminan por agotar al lector, sean una contundente prueba que otorgue el estatuto de verdadero a su relato. El efecto de esta acumulación no deja de ser interesante o valioso. La búsqueda del estatuto de verdadero es central en textos testimoniales. Al parecer es la complejidad misma del acontecimiento el que exige una opción clara entre la cantidad versus la calidad. Ahora bien, la cantidad de entrevistas realizadas por Sacco, más su estadía, la que se convierte en 
un supra testimonio, el único que cumpliría con su ética de los cereales, generan un efecto singular. La suma de ambos elementos termina por generar un testimonio sólido, que reproduce eficazmente una determinada condición humana. Si bien el lector no se lleva en su conciencia ningún solo nombre, sí lo hace de una totalidad que podríamos denominar el pueblo palestino. Circulan por nuestra mente infinidad de rostros e historias, todas ellas conforman la situación palestina que sí termina por pesar.

A la brevedad de los testimonios se le suma, como segunda opción que dificulta la identificación del lector, la opción representativa en extremo caricaturesca ${ }^{8}$. La situación del pueblo palestino es en general ajena al ciudadano promedio occidental, ya sea americano o europeo. Se le percibe como un otro en relación al lector occidental. Esa otredad, en este caso, es sugerida desde el paratexto de Edward Said, autor del famoso ensayo Orientalismo. Los palestinos calzan en este concepto de orientales, es decir, exóticos y distintos. Pensemos ahora la opción representativa más inclinada hacia el extremo de la caricatura. Si bien el personaje más caricaturesco, como ya habíamos dicho al comienzo, es el mismo Sacco, hay una cierta repetición o estandarización de los rostros palestinos: narices anchas, orejas salidas, comisuras de los labios marcadas y labios anchos y dientes cuadrados. Incluso los rostros de los niños se parecen entre sí y parecen pequeños adultos más que niños (aunque esto puede ser un efecto deseado para mostrar la niñez como perdida). La representación tiene como efecto una cierta homogenización del sujeto palestino, todos los rostros se parecen y el lector no logra recordarlos. En especial el caso de los ancianos y las madres: los rostros en primer plano de ellos son muy parecidos y no logramos distinguirlos con claridad. Casi podríamos afirmar que se trata de una estética feísta. Pero lo central de este estilo es, insistimos, el efecto de homogenización del rostro palestino: todos se parecen y así más difícil retener a uno de ellos como persona única.

Ahora bien, cabe preguntarse si la identificación, entendida como una cercanía, es el único camino válido para asumir una toma de conciencia en relación al otro. Si bien no está dicho de modo explícito en Palestina, sí se sobreentiende que la toma de conciencia estaría supeditada a una primera cercanía afectiva en la cual se perciba al otro como a un vecino. O dicho de otro modo: ese otro podría ser yo. Mirado así, a este comportamiento moral le subyacería una cierta lógica de la conveniencia o la ganancia: el despertar moral adviene porque en el fondo me veo en ese otro y sus peligros son los míos. No deseo

8 En este punto disentimos parcialmente de la tesis de la identificación antes explicada de Scott McCloud, ya que no siempre se produce el efecto de identificación deseado. Seguimos más bien la postura de Rosenblatt y Lunsford en Critique, Caricature, and Compulsion in Joe Sacco's Comic Journalism: "The caricature here walks a fine line: are the protesters being portrayed as crazed beast, undermining the legitimacy of their political acts?" (77). La cita hace alusión al modo en que Sacco representa a los palestinos en una protesta: bocas abiertas, rostros desfigurados y feroces. 
que eso me pase a mí también. Detrás de la identificación como respuesta a la alteridad lo que se esconde es un cierto egoísmo9. Lo que prima en la identificación del "yo soy" es, más que una respuesta ética, una respuesta de supervivencia y de seguridad. Ahora bien, más complejo resulta entonces ese deseado compromiso de conciencia cuando la identificación no se logra del todo.

Como venimos sosteniendo, esto es así, en parte por la brevedad de los testimonios, en parte por la representación caricaturesca y, ahora llegamos a lo fundamental... no se logra debido a un cierto grado de irreductibilidad en la otredad del palestino. Por más que Sacco nos lo muestre en su día a día, en su dolor y rostro de madre, aun así, ese palestino nos es otro. Esto lo grafica el mismo Sacco en varios momentos: cuando ve a las mujeres cubiertas por el paño, cuando conversa con el abogado y nos enteramos de las costumbres salvajes de los hombres contra sus esposas, etc., etc. ${ }^{10}$. El palestino posee algo de irreductible, tanto así que se hace difícil pronunciar la frase: yo soy palestino, yo soy un refugiado de la Franja de Gaza. Precisamente, y este el punto álgido en el trabajo y las opciones de Sacco: es que no lo somos. De hecho, fungen como fuerte contraste los momentos de encuentro con personas más occidentalizadas y con las que Sacco comparte un lenguaje y un legado en común. En relación a dos mujeres profesionales israelíes, con las que entabla una cierta amistad al final del relato, afirma: "Naomi y Paula también me resultan familiares... Sus preocupaciones cotidianas me recuerdan las de la gente que conozco en Europa o en los EE.UU" (2004: 261). Visto así, los palestinos son lo no-familiar, en lenguaje heideggeriano representan lo un-heimlich, aquello que infunde miedo o inquieta. Se abre entonces la pregunta esencial: ¿es posible una cierta toma de conciencia en situaciones en las que la identificación no se logra del todo, en las que un residuo de alteridad persiste enconadamente? Tal es la magnitud de la empresa que se desprende de Palestina en la Franja de Gaza. Sacco quiere a toda costa generar esa cercanía. Sin embargo, tras establecer que sus opciones representativas solo lo llevan a un logro parcial y no consiguen del todo el objetivo... brota la pregunta por una conciencia que actué aún en la no identificación. Se trataría de una conciencia menos afectada, más racional, pero, al fin y al cabo, más honesta. Los testimonios de palestinos reunidos por Sacco en esta novela gráfica no hacen que los vea como a mis vecinos, sin embargo, entiendo ese dolor como un dolor del cuál deberíamos hacernos cargo.

9 Para dar un ejemplo concreto, se observa esta respuesta de identificación en el reciente caso del atentado al semanario francés Charlie Hebdo y la frase que circuló ampliamente en los medios: "Yo soy Charlie".

10 Un solo ejemplo: "Es con las mujeres de la calle con las que no me conecto... Me refiero a las mujeres musulmanas que llevan el hijab, el velo que les cubre el cabello, y conjuntos que lo cubren todo excepto la cara y las manos... Aceptémoslo, soy un occidental, he visto un montón de piernas, pelos color naranja y otras expresiones de la moda... Pero esta indumentaria, lo anodina que es... La práctica totalidad de las mujeres que la llevan me pasa desapercibidas, para mí son solo sombras, cifras, como palomas que deambulan por la acera (2004: 137). 
La lectura de Palestina es ciertamente fatigosa. Se nos hace difícil llegar al final. También anhelamos la ducha tibia y el retorno a un espacio más familiar como un restaurante o un diálogo culto en el que no se nos mencione más el día a día del palestino medio. Y sin embargo, aun anhelando este regreso a nuestro mundo estable, seguro y occidental, ya fuimos y volvimos, de la mano de Sacco y sus testimonios, a ese desolador mundo otro. $Y$ no podemos sacárnoslo, querámoslo o no, de nuestras conciencias. Aunque quizás se trate, más que de una toma de conciencia solidaria, de una conciencia de culpa ${ }^{11}$. Una toma de conciencia que no se base en la identificación solo puede basarse en principios universales de normas y comportamientos civiles. Tal es la orientación que desde el "Prólogo del autor" pareciera advertirnos Sacco. Según él, y aquí volvemos a una cita del comienzo, el conflicto persistirá "hasta que este hecho (la ocupación israelí) se trate como un tema de ley internacional y de derechos humanos básicos" (2004: sin número). En síntesis, tanto el lugar de enunciación ambiguo, la figura del antihéroe y las diversas técnicas para representar los testimonios ya descritas, no conducen del todo a la deseada identificación. Sin embargo, considerando la complejidad del hecho mismo, su estatuto de irrepresentable, creemos que los logros de Sacco no son menores. Las opciones representativas y técnicas gráficas utilizadas contribuyen significativamente a formar una toma de conciencia, teñida ciertamente de culpa, pero conciencia al fin y al cabo. Quizás, el camino fallido de la ética de los cereales de Sacco, no hace más que poner en evidencia la necesidad urgente de nuevas modalidades representativas para situaciones como las descritas. Visto así, Palestina. En la Franja de Gaza, se convierte en un claro referente de escritura límite.

\section{REFERENCIAS BIBLIOGRÁFICAS}

ARROYO REDONDO, S. (2012). "Formas híbridas de narrativa: reflexiones sobre el cómic autobiográfico". Escritura e imagen 8, 103-124.

BAETENS, J. y FREY, H. (2015). The Graphic Novel. An Introduction. Cambridge: UP.

DÍAZ DE GUEREÑU, JM. (2014). "Historietas de la guerra de Bosnia: testimonio y género". Hacia un comic de autor. A propósito de Arrugas y otras novelas gráficas, 59-102. Bilbao: Universidad de Deusto.

CARRIER, D. (2000). The aesthetics of comics. Pennsylvania: Pennsylvania State University.

GARCÍA, S. (2010). La novela gráfica. Bilbao: Astiberri.

GROTH, G. (2011). "Joe Sacco on Footnotes in Gaza”. The Comic Journal, 301, 376-426.

HATFIELD, C. (2005). Alternative Comics. Jackson: UP of Mississipi.

11 Hay varias entrevistas que, de hecho, terminan en una fuerte imprecación del entrevistado a Sacco. Como exigiendo una toma de postura y un accionar concreto de su parte. Sacco se ve en serios aprietos y no logra satisfacer las demandas de sus interlocutores. Ver a modo de ejemplo, el final de la entrevista con la madre anciana en la página 242. 
LACAPRA, D. (2006). Historia en tránsito: experiencia, identidad, teoría crítica. México: F.C.E.

LAZZARA, M. J. (2007). Prismas de la memoria: narración y trauma en la transición chilena. Santiago: Editorial Cuarto Propio.

LEVI, P. (2006). Trilogía de Auschwitz. Si esto es un hombre. La tregua. Los hundidos y los salvados. Barcelona: Océano.

LUNSFORD, A., y ROSENBLATT, A. (2010). “Critique, Caricature, and Compulsion in Joe Sacco's Comics Journalism". The Rise of the American Comic Artist. Creators and Contexts. Paul Williams y James Lyons (eds.) 68-87. Jackson: UP Mississipi.

MCCLOUD, S. (1994). Understanding Comics. The invisible art. NY: Harper Collins P. Goggin y Hassler (eds), 166-177. Jefferson, NC: McFarland.

MELERO DOMINGO, J. (2012). “Footnotes in Gaza. El cómic-reportaje como género periodístico”. Madrid, Servicio de Publicaciones de la Universidad Complutense 18. 2 (julio-diciembre), 541 561.

PERIS BLANES, J. (2005). La imposible voz. Memoria y representación de los campos de concentración en Chile: la posición del testigo. Santiago: Editorial Cuarto Propio.

RICOEUR, P. (2004). Tiempo y Narración. México: Siglo XXI editores, 3 vols.

SACCO, J. (2004). Palestina. En la Franja de Gaza. Barcelona: Planeta DeAgostini.

TRABADO, J.M. (2013). La novela gráfica. Poéticas y modelos narrativos. Madrid: Arco-Libros.

THOMAS, I. (1990). Comics as Culture. Jackson and London: UP of Mississippi.

VERSACI, R. (2007). "The new journalism revisited. Comic Books vs. Reportage". En This Book contains Graphic Language. Comics as Literature, 109-135. New York, London: Continuum.

WHITE, H. (2003). El texto histórico como artefacto literario. Barcelona: Paidós.

WORDEN, D. (2015). The Comics of Joe Sacco. Journalism in a visual world. Jackson: UP of Mississipi.

WOO, B. (2010). "Reconsidering Comics Journalism: information and experience in Joe Sacco's Palestine". En The Rise and Reason of Comics and Graphic Literature: Critical Essays on the Form.

Recibido el 24 de marzo de 2016.

Aceptado el 1 de noviembre de 2016. 